\title{
Pregnancy and the skeletal complications of sickle cell disease
}

\author{
Oladele Akinla \\ M.B., F.R.C.S., M.R.C.O.G. \\ Lagos University Teaching Hospital*
}

\begin{abstract}
Summary
An account is given of three patients with the skeletal complications of sickle cell disease in association with pregnancy. Avascular necrosis of bone and acute osteomyelitis are the usual forms of these complications.

The associated high perinatal mortality is probably due to the constant hypoxia to which the foetus is exposed during both pregnancy and labour.
\end{abstract}

\section{Introduction}

Sickle cell anaemia (HbSS) and sickle cell haemoglobin-C disease (HbSC) are the varieties of sickle cell disease usually encountered during pregnancy in Nigeria (Akinla, 1972). The incidence, though low, is certainly increasing. This is because young girls with a chronic haemolytic anaemia who in the past readily succumbed to intercurrent disease and malnutrition are now, with improved medical facilities, surviving to child-bearing age (Hendrickse \& WatsonWilliams, 1966).

The characteristic crises and other complications of sickle cell disease tend to be more frequent and more severe during pregnancy than in the nonpregnant state, and this fact has a direct bearing on the associated high maternal morbidity and perinatal mortality rates (Akinla, 1972). This is especially true of the skeletal complications.

During the period from September 1966 to December 1970 , forty-four patients with sickle cell disease received ante-natal care and were subsequently confined in the Obstetric Unit of the Lagos University Teaching Hospital. The Hb genotypes of these patients were as follows: HbSS, sixteen patients; HbSC, twenty-six patients; $\mathrm{HbCC}$, two patients.

A total of 6017 patients were managed in the unit during this period, and of these, 5465 had their $\mathrm{Hb}$ genotypes determined and recorded. The patients with sickle cell disease thus constituted $0.81 \%$ of this population. The maternal and foetal complications of the pregnancies in these patients as well as the eventual outcome have been the subject of a recent report (Akinla, 1972).

* Correspondence: Dr O. Akinla, Private Mail Bag 12003, Lagos, Nigeria.
Three of the patients had severe skeletal complications: one with $\mathrm{HbSC}$ had avascular necrosis of bone in between pregnancies while two with HbSS had episodes of acute osteomyelitis, during pregnancy in one, and during the immediate post-partum period in the other. They constitute the subject of the present report.

\section{Case reports}

Case No. 1

Mrs B.A. aged 26, para $1^{+0}$, was admitted to hospital on 9 September 1965 with severe pain in the right hip and painful swelling of both knees associated with fever and weight loss. On examination she was pale, ill and febrile $\left(100^{\circ} \mathrm{F}\right)$. The knees were swollen, warm and tender. All movements in the right hip were severely limited by pain.

Investigations: (a) Haematology. The sickling test was positive, and the $\mathrm{Hb}$ genotype $\mathrm{SC}$. The $\mathrm{Hb}$ was $8.9 \mathrm{~g} / 100 \mathrm{ml}$ and the WBC $8700 / \mathrm{mm}^{3}$.

(b) $X$-rays. The right hip showed considerable loss of joint space with bone destruction (Fig. 1).

(c) Microbiology. Sterile pus was aspirated from the right hip on 12 November 1965, and from the left knee on 31 December 1965.

Treatment and follow-up. The patient was in hospital for 6 months, and treatment consisted of rest, analgesics, sedatives, aspiration of pus, a high protein diet, folic acid tablets and prophylactic antibiotics and antimalarials. At the time of a follow-up attendance in September 1970 she was found to be 3 months pregnant, and was promptly referred to the Obstetric Unit.

At booking on 9 October 1970 she was 18 weeks pregnant, the LMP being 4 June 1970 . The $\mathrm{Hb}$ was $10 \cdot 1 \mathrm{~g} / 100 \mathrm{ml}$. The pregnancy was uneventful till 36 weeks when a persistent breech presentation with extended legs was found. A lateral pelvic film showed a true conjugate of $12.2 \mathrm{~cm}$, and at term the baby's weight was clinically assessed to be less than $7 \mathrm{lb}$ $(3200 \mathrm{~g})$. A vaginal delivery was therefore allowed, but unfortunately ended in a fresh stillbirth, weight $6 \frac{1}{2} \mathrm{lb}(3000 \mathrm{~g})$.

In July 1971 the patient was booked at 8 weeks for another confinement. The booking $\mathrm{Hb}$ was $9 \cdot 8 \mathrm{~g} / 100$ 


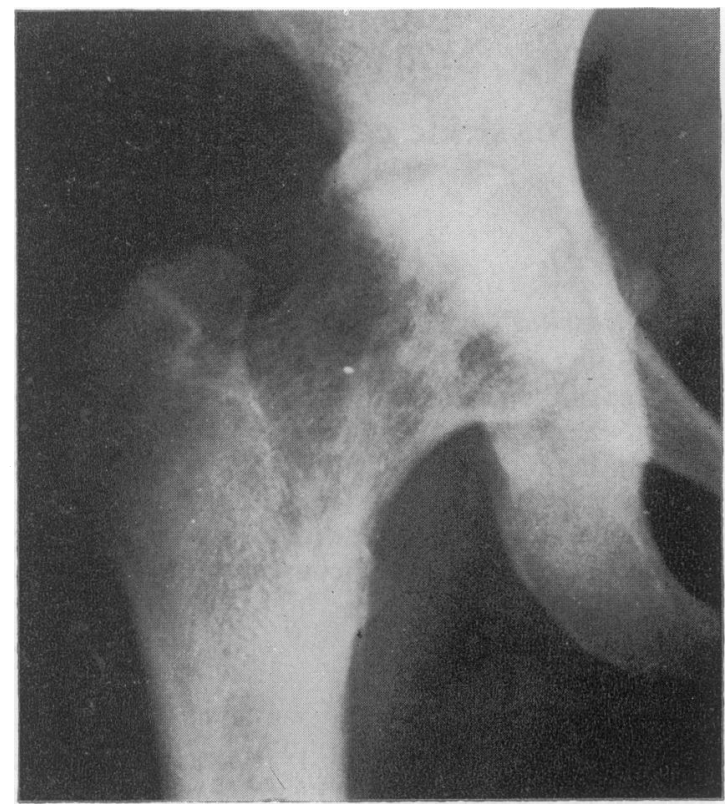

Fig. 1. X-ray of right hip showing loss of joint space and bone destruction.

$\mathrm{ml}$ and the PCV $34 \%$. A breech presentation was again noticed at 34 weeks but external cephalic version was successfuly performed. She suffered no crises throughout pregnancy and the skeletal condition remained quiescent. A live baby weighing $7 \mathrm{lb}$ $15 \mathrm{oz}(3600 \mathrm{~g})$ was delivered as a vertex at term.

\section{Case No. 2}

Mrs F.O. aged 22 was a primigravida. She was booked at 16 weeks on 11 March 1970 . The $\mathrm{Hb}$ was $7.9 \mathrm{~g} / 100 \mathrm{ml}$, the sickling test was positive and the $\mathrm{Hb}$ genotype SS. The pregnancy was complicated by episodes of acute pyelonephritis and infarctive sickle cell crises. Labour commenced spontaneously at 38 weeks but was terminated by Caesarian section for foetal and maternal distress. The baby weighed $7 \mathrm{lb} 10 \mathrm{oz}(3500 \mathrm{~g})$ and was a fresh stillbirth.

During the puerperium, the patient developed acute osteomyelitis of the lower end of the right tibia and the middle of the left radius, confirmed by $\mathrm{X}$-ray examination (Fig. 2a and b). It was treated with large doses of antibiotics followed by incision and drainage of pus from both affected sites. Proteus vulgaris and Escherichia coli sensitive to chloramphenicol were isolated from the pus, but no salmonella organisms were found. Slow but satisfactory recovery was achieved.

\section{Case No. 3}

Mrs R.A.S. aged 25 was also a primigravida. She was booked at 24 weeks maturity on 13 February

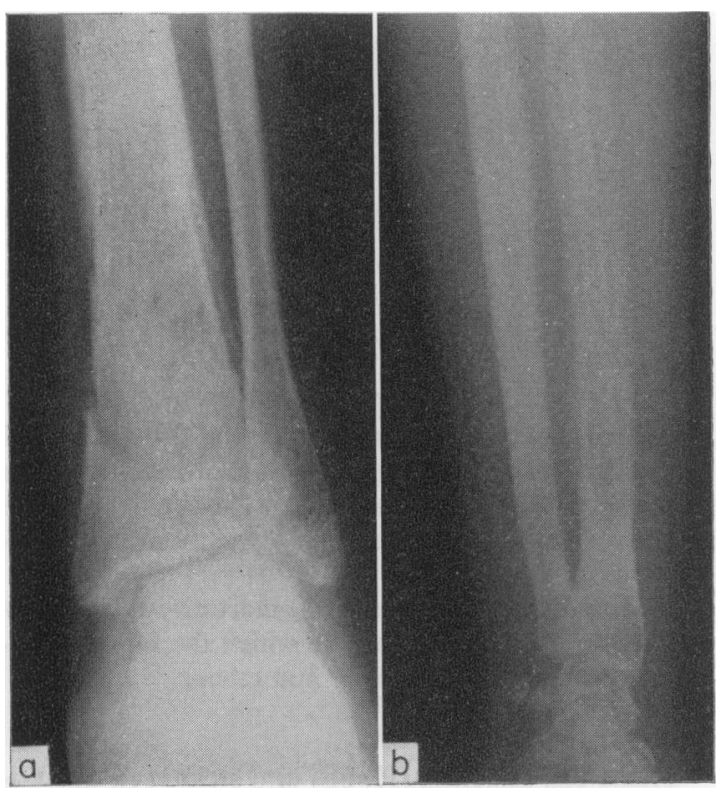

FIG. 2. X-ray of (a) right tibia and (b) left radius showing acute osteomyelitis.

1970. She was first diagnosed as a case of sickle celle anaemia (HbSS) at the age of 14, and had sufferece several attacks of both haemolytic and infarctive crises.

She developed acute osteomyelitis of the upper end of the left humerus 4 months before she became pregnant. She was thin, emaciated and anaemic, $\mathrm{Hb} 7 \cdot 3 \mathrm{~g} / 100 \mathrm{ml}$. Uterine enlargement corresponded with the period of amenorrhoea.

The left upper arm was swollen just distal to the shoulder, and had a discharging sinus on its lateral aspect (Fig. 3). X-ray examination of the left humerus showed evidence of acute osteomyelitis. Culture of pus from the sinus grew Salmonella edinburg sensitive to chloramphenicol, a course of which the patient received.

Labour commenced spontaneously at 38 weeks, and ended in the normal delivery of a live infant which weighed $5 \mathrm{lb} 4 \mathrm{oz}(2380 \mathrm{~g})$.

\section{Discussion}

It is well established that bone and joint infections occur more commonly in patients with sickle cell disease than in normal individuals (Diggs, Pulliam \& King, 1937; Widen \& Cardon, 1961). This is bebecause the bone changes of marrow hyperplasia, thrombosis, infarction, osteoporosis and reactive osteosclerosis seen in sickle cell disease may lead to avascular necrosis and so predispose to the development of superimposed bone infections (Silver, Simon 


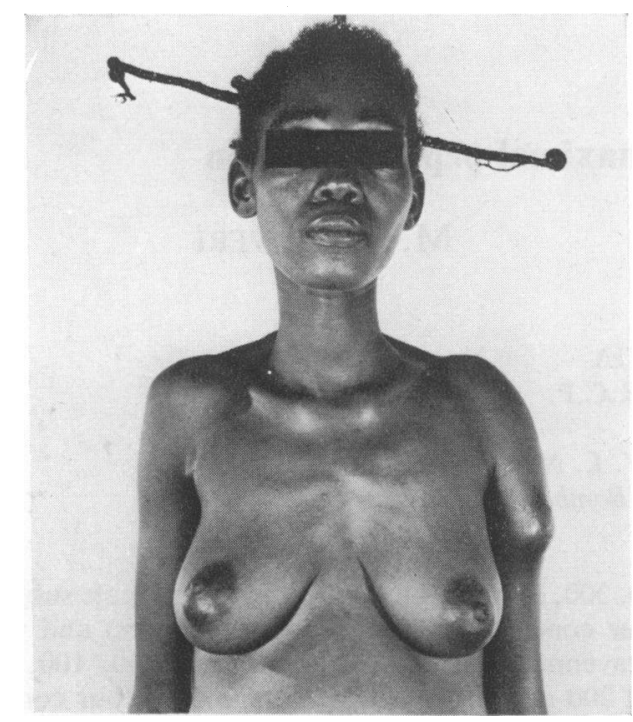

Fig. 3. Patient with swollen left upper arm showing discharging sinus on the lateral aspect.

\& Clement, 1957; Roberts \& Hilburg, 1958). Infarctive sickle cell crises are more frequent and more severe during pregnancy than in the non-pregnant state (Hendrickse \& Watson-Williams, 1966; Akinla, 1972). One can therefore understand the occurrence of avascular necrosis or osteomyelitis in the three cases here reported.

In the first patient, in whom avascular necrosis of the head of the femur occurred in 1965, recovery resulted in complete ankylosis of the hip joint and a shortened femoral neck. When she became pregnant 5 years later therefore she became exposed not only to the maternal complications of sickle cell disease (McCurdy, 1964; Akinla, 1972) but also to those that could arise from the bony lesion: it could become reactivated during pregnancy or the puerperium, and the altered gait and pelvic deformity could give rise to dystocia during childbirth.

Fortunately the patient went through two pregnancies without any crises or a reactivation of the bony lesion. A breech presentation however occurred in both pregnancies, and the bony deformity may have contributed to this malpresentation.

The second case behaved typically like one of sickle cell disease in that she had episodes of acute pyelonephritis as well as haemolytic and infarctive crises during pregnancy. In addition she suffered an attack of acute osteomyelitis following delivery by Caesarian section, probably brought about by the relative hypoxia that prevailed during anaesthesia and surgery.

In the third patient, acute osteomyelitis antedated but continued into pregnancy, and pus obtained from an overlying sinus grew salmonella organisms. The occurrence of salmonella osteomyelitis in patients with sickle cell disease calls for comment. Whereas osteomyelitis rarely occurs in salmonella infections (Widen \& Cardon, 1961) salmonella organisms are conversely rarely cultured in cases of osteomyelitis, the usual organisms being staphylococci and streptococci, and occasionally $B$. Coli and $B$. Proteus. To explain the high incidence of salmonella osteomyelitis in patients with sickle cell disease, Hook et al. (1957) postulated an impaired integrity of the gastro-intestinal tract, due to capillary thrombosis, thus enabling coliform, salmonella and shigella organisms to gain access to the circulation, from where they naturally localize in areas of ischaemia and necrosis, i.e. the bones and joints that are the seat of infarctive crises.

\section{Perinatal mortality}

The perinatal loss in sickle cell disease is known to be high (McCurdy, 1964; Hendrickse \& WatsonWilliams, 1966; Akinla, 1972). It would appear to be higher still in cases with skeletal complications. The foetus is in an environment of constant hypoxia, and should it escape intra-uterine death, it withstands labour and operative delivery poorly, intrapartum death often resulting. Thus the two complicated deliveries (Breech and Caesarian section) ended in fresh stillbirths, while the two spontaneous vertex deliveries survived.

\section{Acknowledgments}

My thanks are due to the Medical Illustration Unit of the College of Medicine, University of Lagos for the illustrations, to Professor A. O. Adesola for useful criticism of the paper, and to Mr I. O. Omoseni for typing the manuscripts.

\section{References}

Akinla, O. (1972) Abnormal haemoglobins and pregnancy. Nigeria Medical Journal, 2, 11.

Diggs, L.W., Pulliam, H.N. \& King, J.C. (1937) The bone changes in sickle cell anaemia. Southern Medical Journal, $30,249$.

HeNDRICKSE, J.P. DEV. \& Watson-Williams, E.J. (1966) The influence of haemoglobinopathies on reproduction. American Journal of Obstetrics and Gynaecology, 94, 739.

Hook, E.W., CAMPbell, C.G., WeEnS, H.S. \& CoOPER, G.R. (1957) Salmonella osteomyelitis in patients with sickle cell anaemia. New England Journal of Medicine, 257, 403.

MCCURDY, P.R. (1964) Abnormal haemoglobins and pregnancy. American Journal of Obstetrics and Gynaecology, 90, 891 .

Roberts, A.R. \& Hilburg, L.E. (1958) Sickle cell disease with salmonella osteomyelitis. Journal of Pediatrics, 52, 170.

Silver, H.K., Simon, J.L. \& Clement, D.H. (1957) Salmonella osteomyelitis and abnormal haemoglobin disease Pediatrics, $20,439$.

WIDEN, A.L. \& CARDON, L. (1961) Salmonella typhimurium osteomyelitis with sickle cell haemoglobin-C disease. Annals of Internal Medicine, 54, 510. 